\title{
Roland Stangl
}

\section{Die kollisionsrechtliche Umsetzung des Art. 13 EuInsVO}

Methodenfindung im Spannungsfeld mitgliedstaatlicher Rechtsstrukturen

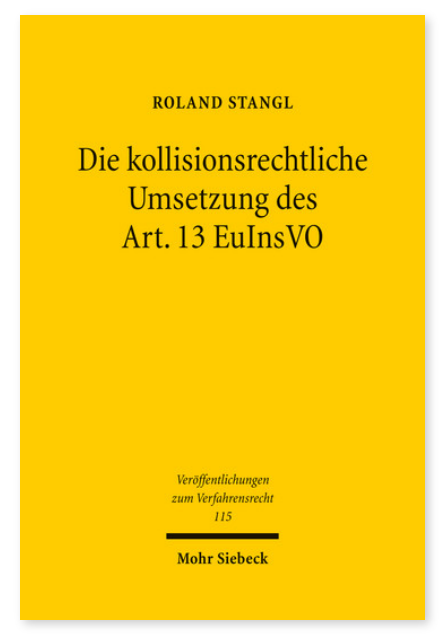

2015. XXIII, 391 Seiten. VVerfR 115

ISBN 978-3-16-155689-0

DOI 10.1628/978-3-16-155689-0

eBook PDF 109,00€

ISBN 978-3-16-153865-0

fadengeheftete Broschur 109,00€
Art. 4 und 13 EulnsVO widmen sich dem Kollisionsrecht der Insolvenzanfechtung. In solchen vereinheitlichten Vorgaben schwingt stets das Versprechen auf ein Mehr an Rechtssicherheit mit. Gerade die Umsetzung des Art. 13 EulnsVO jedoch ist von Unsicherheiten geprägt. Dieser Artikel erlaubt es dem Insolvenzanfechtungsgegner, sich auf die Unangreifbarkeit einer Handlung nach dem für sie maßgeblichen Recht zu berufen. Aber schon der vermeintlich eindeutige Begriff der Handlung bleibt vor dem Hintergrund einzelstaatlicher Rechtsstrukturen ambivalent. Die Ausgestaltung des jeweiligen Übertragungs-, Insolvenzanfechtungs- und Kollisionsrechts hat Einfluss auf das Verständnis dieser Norm. Roland Stangl untersucht am Beispiel Deutschlands, Österreichs, Englands und Frankreichs, welche Wechselwirkungen hier zwischen nationalen Strukturprinzipien und Art. 13 EulnsVO auftreten. Anhand konkreter Beispiele zeigt er auf, wo sich der jeweilige Umgang mit diesem Artikel bisher unterscheidet und wie die Chancen für eine europaweite Einheitslösung stehen.

Roland Stangl Geboren 1982; Studium der Rechtswissenschaften in Freiburg im Breisgau; 2010 Zweites Juristisches Staatsexamen; 2014 Promotion; seit 2014 Rechtsanwalt in Köln.

Jetzt bestellen:

https://mohrsiebeck.com/buch/die-kollisionsrechtliche-umsetzung-des-art-13-euinsvo-9783161556890?no_cache=1 order@mohrsiebeck.com

Telefon: +49 (0)7071-923-17

Telefax: $+49(0) 7071-51104$ 